\title{
Psychosocial factors, disability and quality of life in chronic shoulder pain patients with central sensitization
}

\author{
Prachita P. Walankar, Vrushali P. Panhale, Manali M. Patil \\ Department of Musculoskeletal Physiotherapy, Mahatma Gandhi Mission's College of \\ Physiotherapy, Navi Mumbai, India
}

\begin{abstract}
Chronic shoulder pain is a complex and multidimensional phenomenon with multiple causative factors involved in its perpetuation. Alteration of central nervous system processing along with the central sensitization is a predominant feature in chronic pain. Reduction in physical function has an impact on the psychological well-being of an individual. The aim of the study was to compare pain, kinesiophobia, catastrophizing, disability and quality of life in chronic shoulder pain patients with and without central sensitization. Eighty chronic unilateral shoulder pain patients in the age group of 40 to 60 years were recruited. Of them, 38
\end{abstract}

Correspondence: Prachita Walankar, Department of Musculoskeletal Physiotherapy, Mahatma Gandhi Mission's College of Physiotherapy, Sector 1, Kamothe, Navi Mumbai, Maharashtra, India.

Tel.: 9967102303

E-mail: prachita30@gmail.com

Key words: Central sensitization, chronic shoulder pain, disability, kinesiophobia, quality of life.

Contributions: PPW, conception of design, acquisition, analysis and interpretation of data, writing the draft, editing the draft; VPP, conception of design, acquisition, analysis and interpretation of data, writing the draft, editing the draft; MMP, conception of design, acquisition, analysis and interpretation of data, writing the draft.

Conflict of interests: The authors declare no conflict of interests.

Acknowledgments: The authors would like to thank all the participants in the study.

Funding: None

Ethical approval and consent to participate: the study was approved by the Institutional Ethical Review Committee of the author's institution. Informed consent was obtained.

Availability of data and materials: all the data and materials are available within the text.

Received for publication: 4 February 2020.

Revision received: 17 May 2020.

Accepted for publication: 18 May 2020.

This work is licensed under a Creative Commons AttributionNonCommercial 4.0 International License (CC BY-NC 4.0).

${ }^{(C)}$ Copyright: the Author(s), 2020

Licensee PAGEPress, Italy

Health Psychology Research 2020; 8:8874

doi:10.4081/hpr.2020.8874 were chronic shoulder pain with central sensitization and 42 without central sensitization, classified on the basis of central sensitization inventory. Pain catastrophizing was measured using the pain catastrophizing scale, kinesiophobia using Tampa scale of kinesiophobia, disability using Shoulder pain and disability index and quality of life using 36-Item Short Form Health Survey questionnaire was evaluated in both the groups. Increased pain catastrophizing $(\mathrm{p}=0.000)$, kinesiophobia $(\mathrm{p}=0.000)$ and disability $(p=0.000)$ was observed in centrally sensitized chronic shoulder pain patients. Also, physical component summary $(\mathrm{p}=0.000)$ and mental component summary $(\mathrm{p}=0.000)$ of SF-36 quality of life were reduced in chronic shoulder pain with central sensitization as compared to without central sensitization. Hence, these components should be included during assessment which will provide a holistic and multimodal approach towards the understanding, planning and management of chronic shoulder pain patients.

\section{Introduction}

Chronic shoulder pain is a widespread and persistent musculoskeletal condition affecting the community. It has been reported that the point prevalence of shoulder pain ranges from 6.9 to $26 \%$ and lifetime prevalence from 6.7 to $66.7 \%$ in the general population (Luime et al., 2004). It has been observed to be long lasting with $41 \%$ of the patients reporting persistent issues even after one year of the initial episode (Van der Windt et al., 1996). Chronic shoulder pain is a complex and multidimensional phenomenon with multiple causative factors involved in its perpetuation (Martinez-Calderon et al., 2018). The interaction of varied factors like psychological, social, cognitive, behavioural and environmental determine an individual's risk in developing chronic pain (Mogil, 2012; Diatchenko, Fillingim, Smith, \& Maixner, 2013). These factors lead to poor prognosis and explain the reason why there is chance of recurrence after the first episode of acute pain, which results in negative physical and psychological consequences (Gatchel, Peng, Peters, Fuchs, \& Turk, 2007). These factors are linked to different pain mechanisms involved in the pain processing. Primarily, there are four pain mechanisms illustrated in the literature - nociceptive, neuropathic, inflammatory and central sensitisation (Woolf, 2010; Vardeh, Mannion, \& Woolf, 2016). Chronic pain is characterized by the significant alterations in central nervous system processing with augmentation of nociceptive receptors which eventually results in central sensitization (Meyer et al., 1995).

Sensitisation, a nervous system phenomenon, is in concurrence with pain where normally innocuous input is perceived as painful due to increased nociception (Borstad \& Woeste, 2015). It is classified into two types - peripheral sensitisation and central sensitisation, which play a significant role in development of musculoskeletal pain (Arendt-Nielsen, Fernández-de-Las-Peña, \& 
Graven-Nielsen, 2011). Peripheral sensitization is defined as augmentation of nociception during performance of non-painful activities (Borstad \& Woeste, 2015). The International Association for the Study of Pain defined central sensitization as an increased sensitivity of nociceptive neurons in the central nervous system to normal sensory input (Loeser \& Treede, 2008; Woolf, 2011). It is noted that persistent peripheral sensitization leads to modifications in the central nervous system and can lead to central sensitization (Nijs, Van Houdenhove, \& Oostendorp, 2010; Woolf, 2011).

Central sensitization leads to alteration in function of neurons and nociceptive pathways either by augmenting the membrane excitability or by diminishing the inhibitory pathways (Woolf, 1983). There are several factors involved in perpetuation of central sensitization - increased stimulation of wide dynamic range neurons in response to any pain and non-painful stimuli; repetitive stimuli leading to increased nociceptive response and increased activation lasting for a prolonged period after the preliminary stimulus (Latremoliere \& Woolf, 2009). These factors result in cortical reorganization and maladaptive neuroplastic changes further leading to dysfunction of endogenous pain control mechanisms (Latremoliere \& Woolf, 2009).

It is hypothesized that central sensitization is a possible mechanism for the development of chronic pain syndromes (DeSantana \& Sluka, 2008). A systematic review of literature revealed that central nervous system becomes hypersensitive in a patient with unilateral shoulder pain (Sanchis, Lluch, Nijs, Struyf, \& Kangasperko, 2015). It has been reported that psychosocial factors mediate between pathophysiology of the condition and patients' subjective experience of pain and disability (Vranceanu, Barsky, \& Ring, 2009). The role of psychological factors on pain intensity and disability in chronic shoulder pain patients has been evaluated in many studies (Kromer, Sieben, de Bie, \& Bastiaenen, 2014; Chester, Jerosch-Herold, Lewis, \& Shepstone, 2018).

Assessment of pain intensity is followed regularly in both research and clinical practice. It tells us only about the intensity of pain. However, it does not portray the pain perception, about the catastrophizing behaviour or kinesiophobia. It fails to distinguish the neurophysiological mechanisms driving pain perception (Fillingim et al., 2016). Hence, it is not only pain but other psychosocial factors, disability and quality of life should be evaluated in chronic shoulder pain patients with central sensitization. Hence, the primary aim of this study was to compare the level of affection of pain, kinesiophobia, catastrophizing, disability and quality of life in chronic shoulder pain patients with and without central sensitization.

\section{Materials and Methods}

The study was conducted after obtaining approval from the Institutional Research Review Committee. A cross-sectional study using purposive sampling method was conducted from August 2018 to February 2019. A total of eighty chronic shoulder pain patients in the age group of 40 to 60 years reporting unilateral shoulder pain for more than 3 months were recruited. Participants with complete rotator cuff tear, shoulder instability, shoulder dislocation, hemiplegic shoulder pain, any upper extremity surgery, any systemic conditions affecting the neck, back and upper extremity, bilateral shoulder pain, any concomitant cervical pain or injury were excluded from the study. Subjects were informed about the purpose and nature of the study in detail. A written informed consent was signed by the subjects who were willing to participate in the study. Anonymity of the participants and the safety of the information collected was maintained. The study protocol was completed in one session for each subject. Socio-demographic profile including age, gender, dominance (right or left), occupation and education was noted for all the participants.

The central sensitization inventory (CSI), a patient reported outcome measure, is a reliable and valid comprehensive screening instrument for identification of central sensitization (Neblett et al., 2015). The CSI inventory comprises of two sections - Part A and Part B. Part A consisted of 25-item self-report questionnaire with each item assessed on a 5-point Likert scale $(0=$ never and $4=$ always), with total scores ranging from 0-100. Part B evaluates health-related symptoms that are common to Central Sensitization Syndromes. Part B which is not scored was not used in the study. Higher scores indicate more severe central sensitization. A CSI cut-off score of 40 exhibited good sensitivity in identifying central sensitization (Neblett et al., 2013). According to the cut off score of central sensitization inventory, patients were classified into two groups: Group A $(\mathrm{N}=38)$ comprised of patients with central sensitization (CSI Score $\geq 40)$ and group $B(N=42)(C S I$ Score $<40)$ patients without central sensitization.

Pain catastrophizing was evaluated using the pain catastrophizing scale, a 13 item self-report measure divide into three domains - helplessness, magnification, and rumination. Each item is rated on a 4-point Likert scale yielding a total possible score of 52 . Higher the score, higher the pain catastrophizing thoughts are present (Sullivan, Bishop, \& Pivik, 1995).

The Tampa Scale for Kinesophobia, a self-report 17-item measure, was used to assess 'fear of movement-related pain' (Kori, Miller, \& Todd, 1990). Each item was rated on a 4-point Likert scale ( $1=$ strongly disagree to $4=$ strongly agree) yielding score ranging from 17 to 68 . Higher the score, higher is the level of kinesiophobia (Kori et al.,1990).

The Shoulder Pain and Disability Index (SPADI), a 13-item measure, comprises of 2 subscales - pain ( 5 items) and function ( 8 items) was used to assess level of disability. Higher scores indicate higher levels of disability (Roach, Budiman-Mak, Songsiridej, \& Lertratanakul, 1991). The internal consistencies of the SPADI total and subscales of pain and function ranged from 0.86 to 0.95 , and it has demonstrated moderate test-retest reliability of total and subscales cores ( $\mathrm{ICC}=0.64$ to 0.66). (MacDermid, Solomon, \& Prkachin, 2006).

The Quality of Life was evaluated using 36-Item Short Form Health Survey questionnaire (SF-36), a self-administered questionnaire. The components were grouped as Physical Component Summary (PCS) and Mental Component Summary (MCS). PCS includes physical functioning, role limitations due to physical functioning, fatigue and pain whereas MCS includes role limitations due to emotional problems, emotional wellbeing, social functioning and general health. Higher the score, better the quality of life. The SF-36 shows construct validity and good reliability (Cronbach $\mathrm{a}=0.73$ to 0.96 ; test-retest $\mathrm{r}=0.63$ to 0.81 ) (Brazier et al., 1992).

\section{Statistical analysis}

Data was analyzed using Statistical Package for the Social Sciences (SPSS 20.0). Quantitative variables were expressed as mean and standard deviation, while the qualitative variables as absolute numbers and percentages. $P$ value less than 0.05 were considered significant. The normality distribution of the data was evaluated using Shapiro-Wilk test. Independent T-test was performed to compare data between two groups. The association between two variables was assessed using Pearson correlation test. 


\section{Results}

Demographic characteristics in terms of age, gender, dominance, education and occupation are shown in Table 1. Out of 80 chronic shoulder pain patients, $47.5 \%(\mathrm{~N}=38)$ were with central sensitization and $52.5 \%(\mathrm{~N}=42)$ without central sensitization. The mean age was $47.89 \pm 9.54$ and $49.26 \pm 10.7$ years in chronic shoulder pain with and without central sensitization respectively.

There was a significant difference observed in mean values of pain $(\mathrm{p}=0.000)$, pain catastrophizing $(\mathrm{p}=0.000)$, kinesiophobia $(\mathrm{p}=0.000)$ and disability $(\mathrm{p}=0.000)$ scores with higher scores seen in chronic shoulder pain with central sensitization. Likewise, the comparison of mean values of physical component summary $(\mathrm{p}=0.000)$ and mental component summary $(\mathrm{p}=0.000)$ of SF-36 quality of life were found to be statistically significant with reduced values in centrally sensitized chronic shoulder pain patients (Table 2)

Further analysis was conducted in the eighty chronic shoulder pain patients with respect to association of pain, kinesiophobia, pain catastrophizing, disability and quality of life with central sensitization. The association was conducted using Pearson correlation test. It was observed that there was a statistically significant positive correlation between central sensitization and pain $(\mathrm{r}=0.45$, $\mathrm{p}=0.000)$; kinesiophobia $(\mathrm{r}=0.66, \mathrm{p}=0.000)$; pain catastrophizing $(\mathrm{r}=0.71, \mathrm{p}=0.000)$ and disability $(\mathrm{r}=0.71, \mathrm{p}=0.000)$. Also, there was a statistically significant negative correlation between central sensitization and physical component summary $(\mathrm{r}=-0.75, \mathrm{p}=0.000)$ and mental component summary $(\mathrm{r}=-0.77, \mathrm{p}=0.000)$ (Table 3$)$.

\section{Discussion}

The aim of this study was to compare the level of affection of pain, psychological factors, disability and quality of life in chronic shoulder pain patients with and without central sensitization. The results suggest that increased pain severity, pain catastrophizing, kinesiophobia, disability and impaired quality of life were observed in centrally sensitized chronic shoulder pain patients.

Table 1. Demographic characteristics of the participants.

\begin{tabular}{|c|c|c|}
\hline Characteristics & $\begin{array}{l}\text { Chronic shoulder pain with central sensitization, } \\
\qquad(\mathrm{N}=38) \\
\mathrm{n}(\%)\end{array}$ & $\begin{array}{l}\text { Chronic shoulder pain without central sensitization, } \\
\qquad(\mathrm{N}=42) \\
\mathrm{n}(\%)\end{array}$ \\
\hline Age (in years) & $47.89 \pm 9.54$ & $49.26 \pm 10.7$ \\
\hline $\begin{array}{l}\text { Gender } \\
\text { Female } \\
\text { Male }\end{array}$ & $\begin{array}{l}25(65.78) \\
13(34.21)\end{array}$ & $\begin{array}{l}13(30.95) \\
29(69.04)\end{array}$ \\
\hline $\begin{array}{l}\text { Dominance } \\
\text { Right } \\
\text { Left }\end{array}$ & $\begin{array}{c}37(97.36) \\
1(2.63)\end{array}$ & $\begin{array}{c}39(92.85) \\
3(7.14)\end{array}$ \\
\hline $\begin{array}{l}\text { Occupation } \\
\text { Retired } \\
\text { Employed } \\
\text { Unemployed } \\
\text { Leave } \\
\end{array}$ & $\begin{array}{l}4(10.52) \\
6(15.78) \\
22(57.89) \\
6(15.78)\end{array}$ & $\begin{array}{l}7(16.66) \\
13(30.95) \\
12(28.57) \\
10(23.80)\end{array}$ \\
\hline $\begin{array}{l}\text { Education } \\
\text { Degree } \\
\text { Secondary } \\
\text { Primary } \\
\text { Uneducated }\end{array}$ & $\begin{array}{l}2(5.26) \\
7(18.24) \\
21(55.26) \\
8(21.05)\end{array}$ & $\begin{array}{l}12(28.57) \\
7(16.66) \\
16(38.09) \\
7(16.66)\end{array}$ \\
\hline
\end{tabular}

Table 2. Comparison of mean values of pain, kinesophobia, pain catastrophizing, disability and quality of life in chronic shoulder pain in patients with and without central sensitization.

\begin{tabular}{|c|c|c|c|c|}
\hline \multirow[t]{3}{*}{ Variables } & \multirow{2}{*}{$\begin{array}{c}\text { Chronic shoulder pain with central } \\
\text { sensitisation }\end{array}$} & \multirow{2}{*}{$\begin{array}{l}\text { Chronic shoulder pain without centra } \\
\text { sensitisation }\end{array}$} & \multicolumn{2}{|c|}{ Independent t test } \\
\hline & & & t value & P \\
\hline & Mean \pm SD & Mean \pm SD & & \\
\hline Numerical Pain Rating Scale & $7.47 \pm 1.75$ & $5.81 \pm 1.98$ & -3.96 & \\
\hline Central Sensitization Inventory & $48.11 \pm 8.61$ & $21.38 \pm 9.75$ & -12.94 & $.000^{*}$ \\
\hline Pain catastrophizing scale & $24.53 \pm 10.54$ & $4.69 \pm 4.92$ & -10.95 & $.000^{*}$ \\
\hline Tampa Scale of Kinesiophobia & $42.74 \pm 9.49$ & $25.36 \pm 8.56$ & -8.6 & $.000^{*}$ \\
\hline Shoulder Pain and Disability Index & $63.50 \pm 14.69$ & $34.96 \pm 15.17$ & -8.53 & $.000^{*}$ \\
\hline SF-36 & & & & \\
\hline Physical Component Summary & $40.01 \pm 14.97$ & $76.6 \pm 16.84$ & 10.23 & $.000^{*}$ \\
\hline Mental Component Summary & $40.06 \pm 18.51$ & $82.98 \pm 13.43$ & 11.95 & $.000 *$ \\
\hline
\end{tabular}


Also, further correlation of central sensitization with pain, kinesiophobia, pain catastrophizing, disability and quality of life was investigated. A positive correlation was observed between central sensitization and pain, kinesiophobia, pain catastrophizing and disability. A negative correlation was reported between central sensitization and physical component summary and mental component summary of SF-36 quality of life.

Central sensitization leads to impairment in pain inhibitory mechanisms and activates the pain facilitatory pathways (Staud, Craggs, Robinson, Perlstein, \& Price, 2007; Meeus, Nijs, Van de Wauwer, Toeback, \& Truijen, 2008). This leads to increase in central sensitivity and amplifies nociceptive transmission. Also, there is an imbalance observed between the inhibitory and facilitatory pathways, which in turn implies that central sensitization involves alteration in the sensory processing of the brain (Staud et al., 2007). Negative pain perception hinders the healing process and leads to cognitive behavioral changes in the individual (Noten et al., 2017). The psychological and social factors play a mediating role between impairments and perceived disability by an individual (Lindenhovius, Buijze, Kloen, \& Ring, 2008).

This study showed increased kinesiophobia, pain catastrophizing and disability in centrally sensitized shoulder pain. Also, this study observed reduction in physical component and mental component of quality of life in centrally sensitized chronic shoulder pain patients. Kinesiophobia is defined as an excessive and irrational fear to carry out a movement, due to a feeling of vulnerability to a painful injury or re-injury (Kori et al., 1990). After an initial event of injury, there is development of reciprocal process involving pain related fear, catastrophizing thoughts, kinesiophobia and avoidant behavior. This vicious cycle directly hinders the patient's recovery process which leads to the negative pain experience (Vlaeyen \& Linton, 2000). This further causes avoidance of functional activities, increased pain sensitivity, psychologic distress and chronic disability affecting the physical and mental health related quality of life (Rosenstiel \& Keefe, 1983). This in turn acts like a barrier and decreased adherence to therapeutic management (Vlaeyen \& Linton, 2000). Psychological parameters have an influence on pain intensity and disability in people with chronic shoulder pain as shown in recent studies (Kromer et al., 2014; Chester et al., 2018).

This study showed positive correlation between central sensitization and pain, kinesiophobia, pain catastrophizing and disability and negative correlation with quality of life. This is attributed to the fear avoidance model of which is a biopsychosocial conceptualization of chronic pain that forms the basis for explanation of how maladaptive psychological factors influence the perception of pain (Leeuw et al., 2007). This model depicts that an individual perceives pain as a potential threat and exhibits a protective behav-

Table 3. Correlation of pain, kinesiophobia, pain catastrophizing, disability and quality of life with central sensitization in chronic shoulder pain patients.

\begin{tabular}{lcc} 
& \multicolumn{2}{c}{ Central sensitivation } \\
& r value & p value \\
Pain & 0.45 & $0.000^{*}$ \\
Kinesiophobia & 0.66 & $0.000^{*}$ \\
\hline Pain catastrophizing & 0.71 & $0.000^{*}$ \\
Disability & 0.71 & $0.000^{*}$ \\
\hline Quality of life & & \\
Physical component summary & -0.75 & $0.000^{*}$ \\
Mental component summary & -0.77 & $0.000^{*}$ \\
\hline
\end{tabular}

ior towards it in order to prevent further injury (Leeuw et al., 2007). This is necessary when the condition is acute and such behavior is considered as adaptive (Steimer, 2002). On the other hand, as the condition becomes chronic, the pain persists for a prolonged period leading to increased pain perception and maladaptive behavior (Turk \& Wilson, 2010). In this model, the fear of movement lead to catastrophic thoughts. This has an impact on the performance of activities of daily living leading to increased disability and impaired quality of life (Vlaeyen \& Linton, 2000).

Various studies have recommended that a complete understanding of a patient condition should include assessment of psychological factors in conjunction with physical factors. Healthy psychological status is a strong indicator of the relationship between health-related quality of life and self-rated health (Perruccio, Davis, Hogg-Johnson, \& Badley, 2011). From a biopsychosocial standpoint, a recently published systematic review has emphasized the importance of documenting generic and condition-specific outcome measures as part of assessments of shoulder function and pain (Roe, Soberg, Bautz-Holter, \& Ostensjo, 2013). In this present study, there was an integration of generic and condition-specific outcome measures to assess shoulder pain and physical function (SPADI), characteristics and intensity of pain (NRS), psychosocial implications (TSK and PCS), and the impact on health-related quality of life (SF-36) in patients with chronic shoulder pain. This will assist in development of customized evidence-based treatment approaches and facilitate follow-up evaluation (Roe et al., 2013). Therefore, the therapists should recognize these factors through detailed evaluation of the psychological profile of patient which will aid the practitioners in clinical decision-making and provide tailor-made interventions to improve the condition.

\section{Conclusions}

We conclude that increased levels of pain catastrophizing, kinesiophobia and disability were observed in centrally sensitized chronic shoulder pain patients. Quality of life was also seen to be more affected in chronic shoulder pain with central sensitization as compared to without central sensitization. Hence, these components should be included during assessment which will provide a holistic and multimodal approach towards the understanding, planning and management of chronic shoulder pain patients.

\section{References}

Arendt-Nielsen, L., Fernández-de-Las-Peñas, C., \& GravenNielsen, T. (2011). Basic aspects of musculoskeletal pain: from acute to chronic pain. The Journal of Manual and Manipualtive Therapy, 19(4), 186-193.

Borstad, J. \& Woeste, C. (2015). The role of sensitization in musculoskeletal shoulder pain. Brazilian Journal of Physical Therapy, 19(4), 251-257.

Brazier, J.E., Harper, R., Jones, N.M., O’Cathain, A., Thomas, K.J., Usherwood, T., \& Westlake, L. (1992). Validating the SF-36 health survey questionnaire: New outcome measure for primary care. The BMJ, 305(6846), 160-164.

Chester, R., Jerosch-Herold, C., Lewis, J., \& Shepstone, L. (2018). Psychological factors are associated with the outcome of physiotherapy for people with shoulder pain: a multicentre longitudinal cohort study. British Journal of Sports Medicine, 52(4), 269- 
275.

Diatchenko, L., Fillingim, R.B., Smith, S.B., \& Maixner, W. (2013). The phenotypic and genetic signatures of common musculoskeletal pain conditions. Nature Reviews. Rheumatology, 9(6), 340-350.

DeSantana, J.M., \& Sluka, K.A. (2008). Central mechanisms in the maintenance of chronic widespread noninflammatory muscle pain. Current Pain and Headache Reports, 12(5), 338-343.

Fillingim, R.B., Loeser, J.D., Baron, R., \& Edwards, R.R. (2016). Assessment of chronic pain: domains, methods, and mechanisms. The Journal of Pain, 17(9 Suppl): T10-T20.

Gatchel, R.J., Peng, Y.B., Peters, M.L., Fuchs, P.N., \& Turk, D.C. (2007). The biopsychosocial approach to chronic pain: Scientific advances and future directions. Psychological Bulletin, 133(4), 581-624.

Kori, S., Miller, R., Todd, D. (1990). Kinesiophobia: a new view of chronic pain behavior. Pain Management, 3(1), 35-43.

Kromer, T.O., Sieben, J.M., de Bie, R.A., \& Bastiaenen, C.H. (2014). Influence of fear avoidance beliefs on disability in patients with subacromial shoulder pain in primary care: a secondary analysis. Physical Therapy, 94(12), 1775-84.

Latremoliere, A., \& Woolf, C.J. (2009). Central sensitization: a generator of pain hypersensitivity by central neural plasticity. The Journal of Pain, 10(9), 895-926.

Leeuw, M., Goossens, M.E., Linton, S.J., Crombez, G., Boersma, K., \& Vlaeyen, J.W. (2007). The fear-avoidance model of musculoskeletal pain: current state of scientific evidence. The Journal of Behavioural Medicine, 30(1), 77-94.

Lindenhovius, A.L., Buijze, G.A., Kloen, P., \& Ring, D.C. (2008). Correspondence between perceived disability and objective physical impairment after elbow trauma. The Journal of Bone and Joint Surgery. American volume, 90(10), 2090-2097.

Loeser, J.D., \& Treede, R.D. (2008) The Kyoto protocol of IASP Basic Pain Terminology. Pain, 137(3), 473-477.

Luime, J.J., Koes, B.W., Hendriksen, I.J., Burdorf, A., Verhagen A.P., Miedema, H.S., \& Verhaar, J. (2004). Prevalence and incidence of shoulder pain in the general population; a systematic review. Scandinavian Journal of Rheumatology, 33(2), 73-81.

MacDermid, J.C., Solomon, P., \& Prkachin, K. (2006). The Shoulder Pain and Disability Index demonstrates factor, construct and longitudinal validity. BMC Musculoskeletal Disorders, 7, 12.

Martinez-Calderon, J., Meeus, M., Struyf, F., Miguel MoralesAsencio, J., Gijon-Nogueron, G., \& Luque-Suarez, A. (2018). The role of psychological factors in the perpetuation of pain intensity and disability in people with chronic shoulder pain: a systematic review. BMJ Open, 8(4), e020703.

Meeus, M., Nijs, J., Van de Wauwer, N., Toeback, L., \& Truijen, S. (2008). Diffuse noxious inhibitory control is delayed in chronic fatigue syndrome: an experimental study. Pain, 139(2), 439-448.

Meyer, R.A., Campbell, J.N., \& Raja, S.N. (1995) Peripheral neural mechanisms of nociception. In Wall, P.D., Melzack, R. (Ed.). Textbook of pain. 3rd ed., pp.13-44. Edinburgh: Churchill Livingstone.

Mogil, J. S. (2012). Pain genetics: past, present and future. Trends in Genetics, 28(6), 258-266.

Neblett, R., Cohen, H., Choi, Y., Hartzell, M. M., Williams, M., Mayer, T. G., \& Gatchel, R. J. (2013). The central sensitization inventory (CSI): Establishing clinically significant values for identifying central sensitivity syndromes in an outpatient chronic pain sample. Journal of Pain, 14(5), 438-445.

Neblett, R., Hartzell, M.M., Cohen, H., Mayer, T.G., Williams, M., \& Choi, Y. (2015) Ability of the central sensitization inventory to identify central sensitivity syndromes in an outpatient chronic pain sample. The Clinical Journal of Pain, 31(4), 323-32.

Nijs, J., Van Houdenhove, B., \& Oostendorp, R.A. (2010). Recognition of central sensitization in patients with musculoskeletal pain: Application of pain neurophysiology in manual therapy practice. Manual Therapy, 15(2), 135-141.

Noten, S., Struyf, F., Lluch, E., D’ Hoore, M., Van Looveren, E., \& Meeus, M. (2017). Central pain processing in patients with chronic shoulder pain: a systematic literature review. Pain Pract, 17(2):267-280.

Perruccio, A.V., Davis, A.M., Hogg-Johnson, S., \& Badley, E.M. (2011). Importance of self-rated health and mental wellbeing in predicting health outcomes following total joint replacement surgery for osteoarthritis. Arthritis Care \& Research, 63(7), 973-981.

Roach, K.E., Budiman-Mak, E., Songsiridej, N., \& Lertratanakul, Y. (1991) Development of a shoulder pain and disability index. Arthritis Care \& Research, 4(4), 143-149.

Roe, Y., Soberg, H. L., Bautz-Holter, E., \& Ostensjo, S. (2013). A systematic review of measures of shoulder pain and functioning using the International classification of functioning, disability and health (ICF). BMC Musculoskeletal Disorders, 14, 73.

Rosenstiel, A.K., \& Keefe, F.J. (1983). The use of coping strategies in chronic low back pain patients: relationship to patient characteristics and current adjustment. Pain, 17(1), 33-44.

Sanchis, M.N., Lluch, E., Nijs, J., Struyf, F., \& Kangasperko, M. (2015). The role of central sensitization in shoulder pain: A systematic literature review. Seminars in Arthritis and Rheumatism, 44(6), 710-716.

Staud, R., Craggs, J.G., Robinson, M.E., Perlstein, W.M., \& Price, D.D. (2007). Brain activity related to temporal summation of Cfiber evoked pain. Pain, 129 (1-2),130-142.

Steimer, T. (2002). The biology of fear- and anxiety-related behaviors. Dialogues Clinical Neuroscience, 4(3), 231-49.

ent, M.J., Bishop, S.R., \& Pivik, J. (1995). The pain catastrophizing scale: development and validation. Psychological Assessessments, 7(4), 542-32.

Turk, D.C., \& Wilson, H.D. (2010) Fear of pain as a prognostic factor in chronic pain: conceptual models, assessment, and treatment implications. Curr Pain and Headache Reports, 14, 8895.

Vardeh, D, Mannion, R.J., \& Woolf, C.J. (2016). Toward a Mechanism-Based Approach to Pain Diagnosis. The Journal of Pain, 17, 50-69.

Van der Windt, D.A., Koes, B.W., Boeke, A.J., Deville, W., De Jong, B.A., \& Bouter, L.M. (1996). Shoulder disorders in general practice: prognostic indicators of outcome. The British Journal of General Practice, 46(410), 519-23.

Vlaeyen, J.W., \& Linton, S.J. (2000). Fear-avoidance and its consequences in chronic musculoskeletal pain: a state of the art. Pain, 85:317-32.

Vranceanu, A.M., Barsky, A., \& Ring, D. (2009). Psychosocial aspects of disabling musculoskeletal pain. The Journal of Bone and Joint Surgery. American volume, 91(8), 2014-2018.

Woolf, C.J. (1983). Evidence for a central component of post-injury pain hypersensitivity. Nature, 306(5944), 686-8.

Woolf, C.J. (2010). What is this thing called pain? The Journal of Clinical Investigation, 120(11), 3742-3744.

Woolf, C.J. (2011) Central sensitization: implications for the diagnosis and treatment of pain. Pain,152, S2-S15. 